\title{
Coercing into Completeness in Financial Advisory Service Encounters
}

\author{
Kilic, Mehmet ; Heinrich, Peter ; Schwabe, Gerhard
}

\begin{abstract}
In this article, we report on design insights found during the evaluation of an innovative IT-artifact to support financial service encounters. Relating to previous work in this field, we carefully designed the artifact to omit any visualization and enforcement of rigid process structures, as those had turned out to be harmful. Our main design element was a mind-map-like content hierarchy to capture the client's situation. Surprisingly, we noticed that both clients and advisors talked about every information item visible on the screen just for the sake of completeness. They also followed a sequential process apparently inferred from the content hierarchy. We call this phenomenon "coercing into completeness". This phenomenon negatively influences the conversation between client and advisor inducing shorter discussion units and sudden, incomprehensible topic shifts. This article contributes an exploration of this phenomenon and its effects on the collaborative setting.
\end{abstract}

DOI: https://doi.org/10.1145/2675133.2675289

Posted at the Zurich Open Repository and Archive, University of Zurich

ZORA URL: https://doi.org/10.5167/uzh-110685

Conference or Workshop Item

Accepted Version

Originally published at:

Kilic, Mehmet; Heinrich, Peter; Schwabe, Gerhard (2015). Coercing into Completeness in Financial Advisory Service Encounters. In: Proceedings of the 18th ACM Conference on Computer Supported Cooperative Work Social Computing, Vancouver, Canada, 14 March 2015 - 18 March 2015. ACM, 1324-1335.

DOI: https://doi.org/10.1145/2675133.2675289 


\section{Coercing into Completeness in Financial Advisory Service Encounters}

\author{
Mehmet Kilic \\ University of Zurich \\ Binzmühlestr. 14 \\ 8050 Zürich, Switzerland \\ kilic@ifi.uzh.ch
}

\author{
Peter Heinrich \\ University of Zurich \\ Binzmühlestr. 14 \\ 8050 Zürich, Switzerland \\ heinrich@ifi.uzh.ch
}

\author{
Gerhard Schwabe \\ University of Zurich \\ Binzmühlestr. 14 \\ 8050 Zürich, Switzerland \\ schwabe@ifi.uzh.ch
}

\begin{abstract}
In this article, we report on design insights found during the evaluation of an innovative IT-artifact to support financial service encounters. Relating to previous work in this field, we carefully designed the artifact to omit any visualization and enforcement of rigid process structures, as those had turned out to be harmful. Our main design element was a mind-map-like content hierarchy to capture the client's situation. Surprisingly, we noticed that both clients and advisors talked about every information item visible on the screen just for the sake of completeness. They also followed a sequential process apparently inferred from the content hierarchy. We call this phenomenon "coercing into completeness". This phenomenon negatively influences the conversation between client and advisor inducing shorter discussion units and sudden, incomprehensible topic shifts. This article contributes an exploration of this phenomenon and its effects on the collaborative setting.
\end{abstract}

\section{Author Keywords}

financial advisory service; needs elicitation; completeness; exploratory research; design research

\section{ACM Classification Keywords \\ H.5.3 [Group and Organization Interfaces]}

\section{INTRODUCTION}

Performing tasks completely can be an important factor for qualitative work. In medicine, for example, a physician is required to carefully carry out an anamnesis in order to obtain a sound diagnosis. Engineers have to analyze requirements completely in order to design a purposeful solution to the given problem. Factory workers need to perform all steps completely to assemble products. In all those cases a standardization of the workflow can help guiding the ongoing work towards an expected outcome. It can also help to assess the level of work-completion by

\footnotetext{
Permission to make digital or hard copies of all or part of this work for personal or classroom use is granted without fee provided that copies are not made or distributed for profit or commercial advantage and that copies bear this notice and the full citation on the first page. Copyrights for components of this work owned by others than ACM must be honored. Abstracting with credit is permitted. To copy otherwise, or republish, to post on servers or to redistribute to lists, requires prior specific permission and/or a fee. Request permissions from Permissions@acm.org.
}

CSCW '15, March 14 - 18 2015, Vancouver, BC, Canada Copyright is held by the owner/author(s). Publication rights licensed to ACM.

ACM 978-1-4503-2922-4/15/03 ..\$15.00

http://dx.doi.org/10.1145/2675133.2675289 comparing its status to the workflow's definition. However, if processes are defined in too fine-grained manner, this may lead to acceptance problems, as this restricts process participants in an undesired and unnecessary way [14]. Therefore, the level of detail has to be well balanced between optimal guidance and reasonable levels of restriction.

Collaborative settings are even harder to manage, especially if the participants have different opinions on the level of completeness. Financial advisory services, for example, are loaded with different perceptions of completeness. On the one hand, the clients might be primarily interested in having their individual situation and their goals considered completely in order to obtain the best matching financial product. On the other hand, the financial advisor might have his own incentives, and thus his targeted level of completeness might be restricted by the minimum information required to make an offer. In the worst case, the advisor also limits the range of products according to his personal sales goals in order to receive an extra bonus at the year's end. An inherent conflict of interest between the parties is often referred to as "principal-agent-conflict" [6, $16]$ and implies an associated asymmetry of information $[23,24]$. Executives from the bank still might be interested in another level of completeness. They might prefer complete standardization of the advisory process in order to deliver constant service quality and to comply with normative regulations. In general, these different levels of completeness are never explicated and only implicitly communicated among subgroups of the participants.

Scholars and practitioners have tried to support those encounters with IT-based tools in order to dampen the information asymmetry by making the process itself and the information processed transparent to all stakeholders [17]. However, it has been shown that those supportive tools have to be designed with great care, as they might otherwise endanger the social setting [11]. An explicit visualization and enforced guidance through a rigid process "was perceived to be authoritative and deterministic, imposing its process structure upon the users and restricting the user's control of the process" [18]. An implicit process guidance is far superior and even leads to higher levels of perceived process transparency, process control, and higher overall satisfaction with the service encounter [19]. 
We set out to design an IT-tool to support the first and arguably most crucial phase of financial advisory services - namely, the client's needs elicitation. In this initial phase, the current situation of the client is captured as well as his attitudes, preferences, and goals. We designed an advisory-support tool to support this phase. Our main intention was explicitly not to impose any process onto the participants, because we were aware of the different demands of the various stakeholders (clients, advisors, and executives). Based on literature and prior experience with those settings, we opted for a mind-map-like interface to provide maximum freedom with respect to both the process as well as the content used within a service-encounter.

Besides the obvious benefits that our solution has from a management perspective, some participants felt coerced by the tool to adapt the visualized content as process structures and as notion of completeness. We call this phenomenon "coercing into completeness".

In this paper, we introduce the phenomenon of "coercing into completeness" (1) by describing one exemplary context in which it occurs, (2) by describing its manifestation in the particular collaborative setting from the perspectives of the clients and the advisors, and (3) by making conjectures on the reasons why the phenomenon occurs.

Hence, our research questions are:

RQ1: How does coercing into completeness affect the service encounter?

RQ2: Why does coercing into completeness still occur in the absence of any explicit process and progress visualizations within the IT artifact?

The paper ends with a detailed discussion of the phenomenon as well as implications of our findings for the future design of advisory support systems.

\section{RELATED WORK}

Coercing into completeness in single user contexts

Many companies like Google, LinkedIn, and Dropbox provide a feature called "completeness meter". These kinds of progress indicators give the user feedback on how far he or she is while completing a task. These meters are mostly used to motivate new users to add personal information or to complete activities. Myers has shown that people prefer to have progress indicators [15]. Completing a task is intrinsically rewarding. The discrete task completion hypothesis by Skinner states that a completed task is a conditioned reinforcer [25]. Zeigarnik [32] has shown that people have a tendency to remember incomplete tasks better than completed tasks. Uncompleted tasks are kept in memory until they are completed. These open tasks cause an uncomfortable feeling or even tensions and stress. People want to resolve this tension. This is called negative reinforcement in operant conditioning [7]. People want to remove something distasteful. For example, this effect is used in many mobile operating systems with the annoying persistent badge to motivate us to update our apps or to give attention to new messages. We will usually update our apps because we want those annoying numbers to disappear (negative stimulus). In summary, a progress bar bears both effects at the same time: It is possible to achieve something (positive reinforcement) and to complete an undone task (negative reinforcement).

\section{Coercing into completeness in dyadic advisory contexts}

Financial advisory services are predominantly delivered in a dyadic setting and can be divided into three phases [20]: "information collection phase", "information phase", and "recommendation phase". During the encounter, the problem space of the client (information collection) has to be mapped with the solution space (recommendation phase) to identify matching solutions [16]. For this paper, we focus on the first phase, the information collection phase. At the beginning of the advisory session, an information asymmetry is inherently given because the advisor has insufficient knowledge of the current client's situation. During this first phase of the service encounter, this information asymmetry shall be lowered.

In the information collection phase a notion of completeness depends on the desired modus of advicegiving. Literature describes this as a continuum between two extreme positions: either the "Informed Decision Making model" or the "Perfect Agent Model" [8]. In the "Informed Decision Making model", the clients make all decisions by themselves, in contrast to the other model, where the advisor makes all decisions. For the first model, the client needs profound knowledge about the solution space, whereas in the other model, the advisor needs substantial knowledge of the client's problem space [8]. Neither model can be established in practice, as knowledge transfer in either direction is difficult. Transferring all relevant knowledge about the solution space, i.e. financial products, is considered unrealistic for practical settings due to the missing levels of expertise on client's side and the large amount of required information [13]. The transfer of the client's personal situation, needs, and desires without showing the client concrete solutions options is also difficult [16], and is referred to as the "sticky information" problem [28]. Therefore, in practice there will be a mixture of informed decision-making and perfect agent models with missing information on both sides and practically reachable levels of completeness below the theoretical maximum. Of course, the goal is to minimize the amount of information lacking needed to foster informed decision. Based on the limited shared knowledge, we argue that, on the one hand, in traditional advisory settings a sufficient level of completion is mutually perceived, when the clients have told everything they considered to be important for an advisor to develop a purposeful solution. And on the other hand, this sufficient level of completion is also achieved when the advisors have asked everything they perceive relevant in order to give advice (and sell the appropriate products of course). Besides these situational levels of 
completeness, there also exist extrinsic motivations to gain information from the clients that go partially beyond the perceived needs of the participants within the service encounter. Normative regulations like the WpHG (German law on trading bonds) [31] put banks under pressure to establish standards to ensure a minimum of information acquisition with the aim to protect the client from buying unsuited products. Moreover, additional information items gained during personal interactions can be beneficial to the financial institutions for profiling and cross-/up-selling opportunities [27]. During a traditional face-to-face interaction, these additional drivers for completeness can only be transported through the advisor, as the client is unaware of them.

\section{Coercing into completeness in the presence of structures}

Coercing into completeness is a phenomenon that can be analyzed in the context of the role of structures in the appropriation of technology. In his seminal "structuration theory", Giddens [9] pointed out that structures may have unintended consequences and that it is necessary to understand the intentions of the creators and users of the structures to understand the effects of structures. Building on Giddens' work, DeSanctis and Poole [4] developed the Adaptive Structuration Theory. Among other things, it stresses the importance of the "spirit" of an application and proposes different styles of appropriation ranging from direct use to direct negation.

There has been an intensive discourse on the role of structures in collaborative technologies. Researchers from the traditional CSCW disciplines (most prominently represented by Lucy Suchman in the famous dispute on the coordinator-mail system [26]) tend to warn that prestructuring sensitive processes such as communication or collaboration may conflict human cognition or established social norms. Researchers with a more business-oriented perspective (in the case of the coordinator dispute Terry Winograd [30]) tend to stress the organizational benefits of prescribing structures ranging from less misunderstanding to higher productivity. There is even an emerging research stream on "collaboration engineering" $[1,5]$ coercing to prescribe structured collaboration routines to organizational users. While we see more failures than successes with rigid structures in the domain of collaborative technologies, the widespread adoption of ERP systems in organizations indicates that the organizational benefits of information systems can be so important that users adopt the system and the structured work practices even though many dislike them.

The conflict between organizational interests on the one hand and cognition and social norms on the other hand play an important role in pre-structuring financial advisory service encounters. Struggling with principal-agent conflicts $[6,16]$, quality problems, and regulatory requirements [31], banks push hard to establish structured advisory processes. In a straightforward implementation, they are interested in enforcing the process by the required use of a process-oriented software. Nussbaumer et al. [19] have shown that an explicitly visible pre-defined structure of the advisory process (e.g. "information collection phase", "information phase", and "recommendation phase") will incentivize both the advisors and clients to follow this process. Nevertheless, all participants in such a highly structured process were dissatisfied with the whole service encounters because they felt part of a machinery [19], and the interpersonal relationship-building between advisors and clients suffers [11] in an unacceptable manner. Providing the process structure implicitly (hidden) instead of explicitly (visible), and thus leaving the process to the users instead of the information system, proved to be a superior solution $[17,19]$.

\section{Designing IT artifacts to support implicit completeness}

Supporting advisory encounters with appropriately designed IT-artifacts can be beneficial in many ways. Besides the obvious features of process documentation and integration of other information systems, they can also help to make the whole process more transparent to the clients [19] through the use of shared artifacts between client and advisor [16]. But with respect to the information collection phase, IT-artifacts can be used as a way to commonly objectify $[11,29]$ the discussed information items.

IT-artifacts have to be designed carefully so that they do not interfere with the fragile social setting, which is given in any dyadic service encounter. As stated before, it has been demonstrated that enforced process guidance has strong negative effects on the acceptance of such solutions [18]. However, visualizations and interaction models without fixed structures like "loose widgets" and the "zoom and filter" metaphor have been evaluated to be far more successful than "PowerPoint-like" step-by-step metaphors of process guidance [19]. Such representations deliberately omit a notion of beginning, completion, or progress of the current task or process. Hence, negotiating on completeness should still happen between the participants as within traditional pen and paper-based encounters.

This stream of research leaves open the following issue: Why did the advisor and the client in our setting strive for completeness, although the software did not explicitly visualize or enforce it?

\section{RESEARCH FRAMEWORK}

The methodology used for the research project can be conceptualized as exploratory research [2], emerging from design science research [12] (DSR) activities. Thus, this paper generally follows a structure typical for DSR-related publications [10] and describes all of the six typical DSR activities [21]: (1) problem identification, (2) objectives of a solution, (3) design and development, (4) demonstration, (5) evaluation, and (6) communication. The introduction covers (1) and (2), whereas the artifact description covers (3) and (4). However, the paper focuses especially on the evaluation (5). In contrast to "confirmatory research" [2], 
where the fulfillment of the solution objectives is demonstrated, we use the evaluation as a vehicle to explore why the observed phenomenon emerged and how it manifested itself. Therefore, this paper has an in-depth results and discussion section, where we reason about the factors that lead to coercing into completeness. The last activity (6) - namely, the communication of the results is the purpose of this paper.

According to Briggs [2], the core contribution of exploratory design research is the description of new phenomena and/or its emergence in new contexts. In this paper, we identify and describe the "phenomenon of coercing into completeness" in the context of dyadic advisory service encounters, in which it occurred and started the discussion on possible explanations and factors that lead to the occurrence of this phenomenon.

\section{INITIAL IMPLEMENTATION OF THE ARTIFACT}

Following the DSR methodology [22], we have specified, designed, implemented, and evaluated an IT-prototype. In that research project, we worked in close cooperation with a major Swiss retail bank.

The main design rationale was to support advisors and clients during the needs elicitation process. Therefore, we intended to support the collaboration with technology to enhance the understanding of the client's situation. Together, advisors and clients should create a "picture" of the client's situation and needs. The advisor should have a means to externalize, organize, and discuss the client's information and to summarize the client's themes using this picture. The client should observe that the data was collected transparently and have the opportunity to make immediate corrections, if necessary. In consequence, the advisors' understanding of the clients' situation should be externalized and be verifiable for the client. Furthermore, to overcome the sticky information needs problem, the client should be stimulated to talk about additional topics, which were visualized on the display serving as prompts but not asking for information directly. From an organizational point of view, the bank is interested in collecting information in a holistic manner and to analyze this data. The bank wants to know its clients to unhide up- or crossselling potentials and use them for marketing actions. Therefore, the data should be structured and digitalized. If this data is seized electronically, it is possible to transfer it into a customer relationship management (CRM) system for further analysis.
To guide the design of our artifact, we choose the metaphor of a mind-map to support the information collection phase, as it fulfills the aforementioned demands of providing a flexible and adaptive content structure. Computer supported mind-maps have been shown to be applicable in collaborative settings and have also proven to be beneficial to collaboration in terms of leveling the amount of contribution between the collaborating participants [3].

\section{Artifact design}

The IT-prototype ("Needs Map") was designed with a mind-map analogy displaying the text "me" and the name of the client in the middle and six connected branches as a start: work, residence, family, leisure, finance, and assistance. Stimulating information items, which could be attached to the existing structure, were displayed adaptively with respect to the currently selected item within a large list on the sidebar: selecting one item within the map showed information items related to this branch on the right sidebar. For example, by selecting the branch "work" the items "job", "part time job", "study", and "career" were shown (see Figure 1).

There are three kinds of information items available: information regarding the current situation (such as the current job), concrete goals (such as buying a car), and wishes (for example, goals in future such as buying a family home). The interaction to assign an information item to a branch or another item is realized by dragging and dropping an item on the touchscreen from the right side near to the selected branch or item. There was no limit on the amount and level of items, which could be attached to a branch or another item. It is also possible to add one-time or monthly income and expense information to every information item. The six initial branches (see Figure 1) provided an opportunity to structure the discussed information. The additional information items were provided to stimulate the participants during the needs elicitation phase.

It was intended that clients tell about their current situation, needs, and goals, and that the advisors organize this information in the map in an appropriate branch. We also expected that advisors would use the inherent features of a mind-map, especially the possibility to extend the given structure according to the conversation. In doing so, the client has the opportunity to see transparently how the information is recorded and to correct wrong information. 


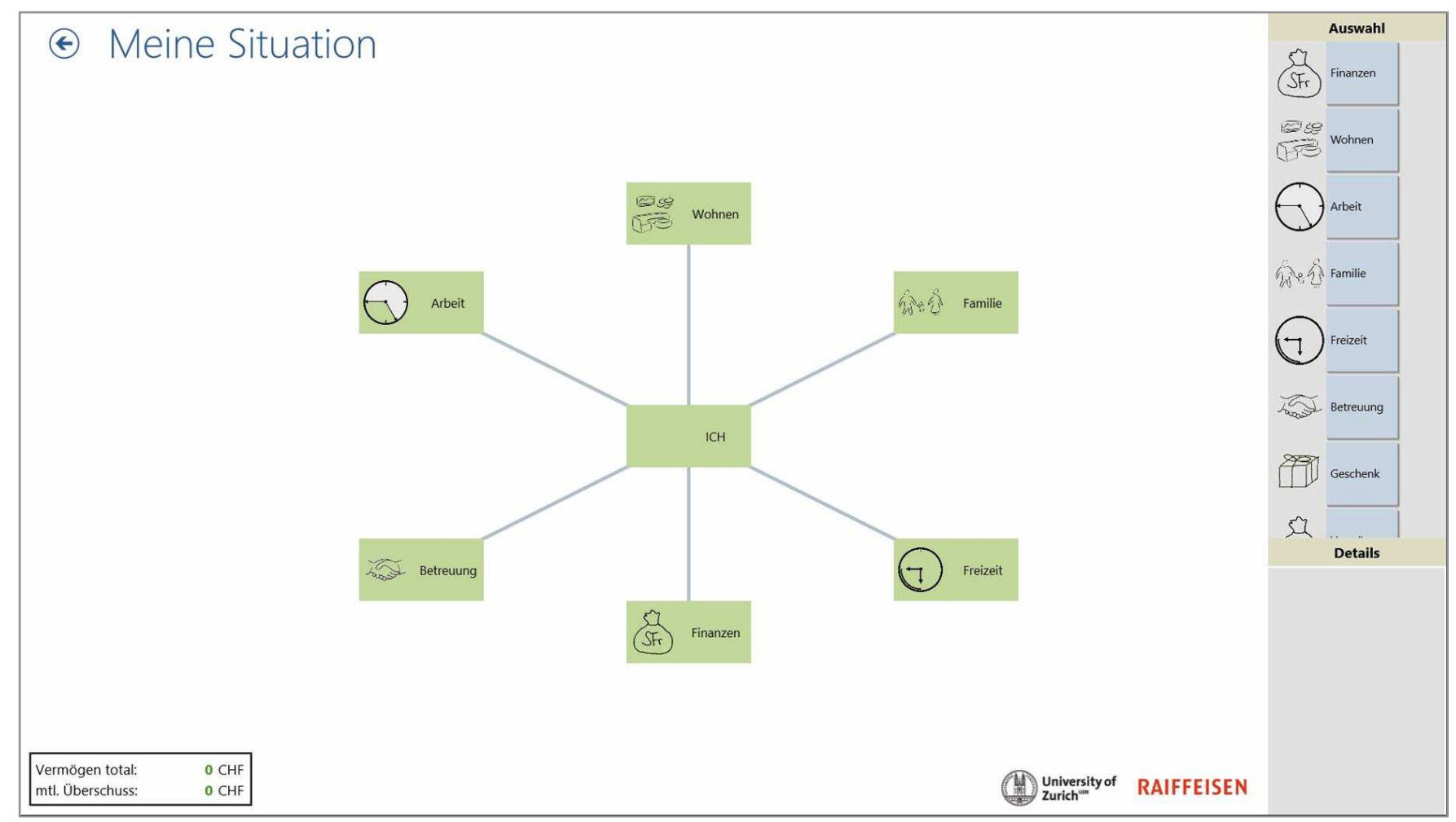

Figure 1. Start screen with empty mind-map. Translation from German:

Meine Situation - my situation, Arbeit - work, Wohnen - residence, Familie - family, Freizeit - leisure, Finanzen - finance, Betreuung - assistance

\section{EVALUATION}

\section{Data collection}

The evaluation of the IT-prototype was accomplished with 16 experienced financial advisors and 48 potential clients (bachelor students from a business informatics course) in a realistic setting. During the advisory service encounter, the participants worked with our IT-prototype. The software was executed on a tabletop computer (a 27-inch touchscreen). The physical environment was designed to enable both participants to interact with the system. The evaluation was conducted as a within-subject design. Thus, every client took part in two advisory service encounter treatments: one traditional pen and paper encounter and one supported by the IT-artifact. The evaluation was carried out over eight days. On every day, two advisors were present onsite and each of them conducted six advisory sessions (three traditional, three IT-supported). Preceding the evaluation, the advisors were first trained one week prior through video explanations and written training material. On the day of the evaluation, each advisor received 60 minutes of personal hands-on training with the artifact.

After the clients had received their two treatments, they were interviewed. Advisors were interviewed at the end of each test day. The interviews were conducted in the form of a semi-structured interview of approximately 30 minutes duration for the clients and approximately 45 minutes for the advisors on average. Video-recordings were taken of the encounters. Screencasts were also recorded for the ITartifact supported encounters.

\section{Results}

To broadly elicit data about the phenomenon, we studied the resulting mind-maps from the sessions, the conversations, and interactions between clients and advisors and how the participants perceived the encounter. The mind-maps were extracted from the screencasts, the conversations were analyzed through the video recordings, and the perceptions of the participants were mainly extracted from the interview data as well as from comments made during the video-recordings. Within each following section, we briefly describe how the data sources were analyzed before presenting the results.

Manifestation of coercing into completeness in the resulting mind-maps

We assessed the result of the mind-maps by capturing the state of the map after the last interaction with it.

In almost all advisory sessions the participants filled out at least five of the provided six branches with personal information of the client (see Figures 2 and 3). Additionally, in most sessions they also talked about the branches that were not filled, but there was either no information to fill out or they decided to leave the branches empty. For example, when the clients were not married or in a partnership they decided not to record this in the family branch (see Figure 3). One advisor of 16 did not really use 
the mind-map; she filled only the "finance" branch with minimal information.

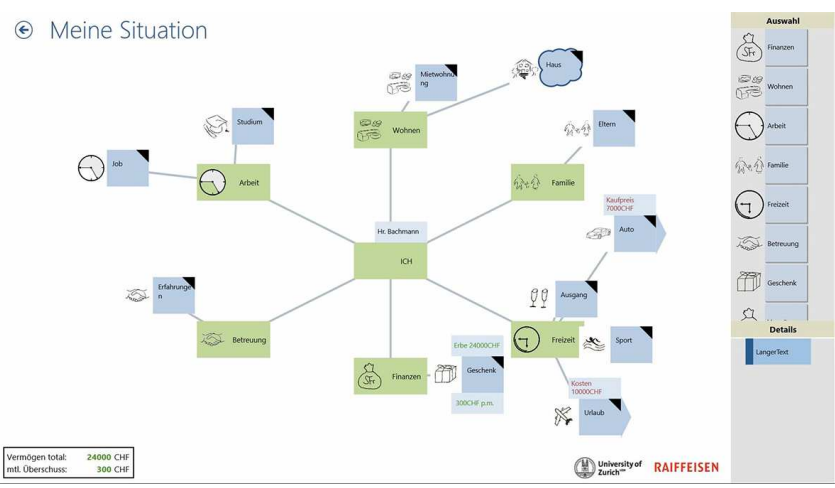

Figure 2. Example of completely filled mind-map

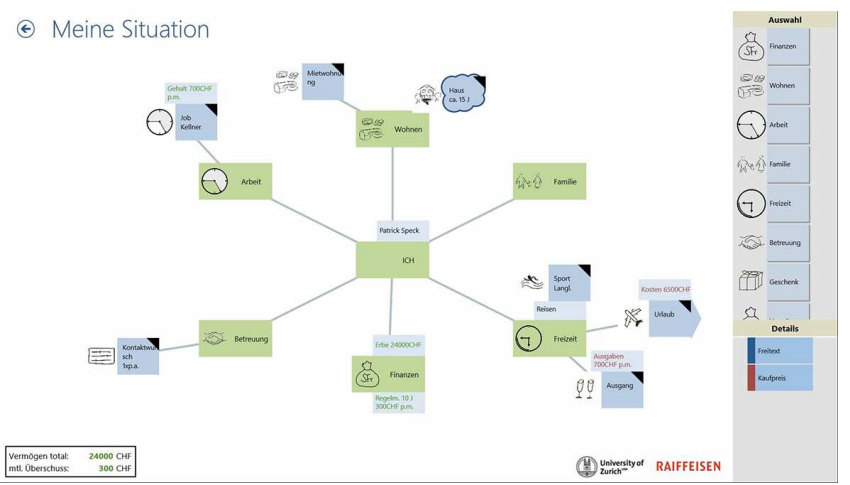

Figure 3: Example of mind-map with empty family branch.

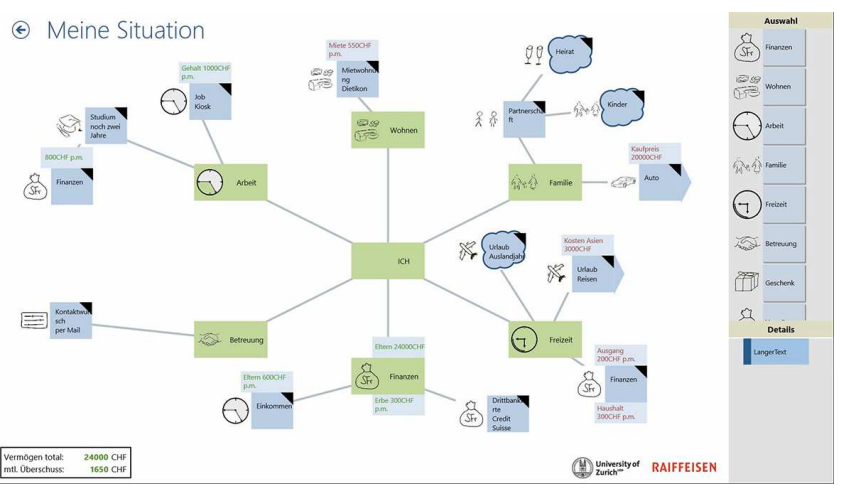

Figure 4: Example of filled mind-map with two levels.

Examples of resulting mind-maps are shown in Figures 2, 3 , and 4. Figure 2 shows a mind-map where at least one information item is attached to a branch, so they have talked about the topic of each branch and recorded the corresponding information. In Figure 3, a mind-map is shown where the family branch is left empty. The mindmaps were mostly filled out in a broad and rather superficial manner. The participants only used one level of depth. From all 48 advisory sessions, only in one session did the participants create items on the second level (see Figure 4). In the remaining 47 sessions the information items were directly attached to a branch.
Manifestation of coercing into completeness in the conversation

By analyzing the screencast alongside the video recordings, we can assess the structure and flow of conversation. In this section, we present a two-step approach analyzing the structure of the conversation. (1) We analyze in which order the topics were discussed within the IT-supported setting. (2) Then, we analyze the transitions between the discussed topics to shed light on the question of how the presence of the artifact changed the discussion behavior of the participants.

In the first step, we analyzed 16 video-recorded sessions and traced the sequence of the discussion topics (see Table 1). For this analysis, we included each advisor's last ITsupported session in the sample. We argue that in the last session the advisors showed the most proficient use of the IT-artifact and were well accustomed to the setting.

Seven advisors start with the branch "work" and talk about the topics in a clockwise direction. Four advisors start with another branch ( $2 \mathrm{x}$ finance, $1 \mathrm{x}$ residence, and $1 \mathrm{x}$ leisure), go to "work", and then go further in a clockwise direction. In summary, 11 advisors start with "work" as the first or second topic and then follow a clockwise structure. When all paths are visualized together, (Figure 5) a pattern emerges and reveals that most advisors follow an identical path. Four advisors do not follow an identifiable pattern. One advisor does not make use of the mind-map at all. Those five were omitted in the visualization for clarity.

In the second step, we took another sample. As we assume that the conversation behavior is strongly related to the individual advisor's personality, we only select advisors with comparable customer satisfaction ratings in the traditional encounter. We analyzed the pairwise recordings from 8 advisors and 8 clients, including 8 traditional encounters and 8 IT-supported ones. Thus, there were 16 sessions in total.

An analysis of how many conversation sequences are present within the information collection phase reveals that significantly more sequences are present within the ITsupported encounter compared to the traditional one. For the analysis, we have transcribed the participant's utterances and identified conversation sequences. One conversation sequence is characterized by the amount of adjacency pairs, i.e. pairs where the question of the advisor is related to the ongoing discussion or answer of the client. Every time the advisor asks a question not related to the ongoing discussion, a new sequence starts.

In the IT-supported encounter the conversations consisted on average of $7.9(\mathrm{sd}=2.17)$ sequences, while the traditional ones only had 4.5 ( $\mathrm{sd}=2.07)$ sequences. A two-sided pairedsample T-test reveals this difference to be significant $(\mathrm{T}(7)=4.473, \mathrm{p}<=0.005)$. However, the numerous sequences of IT-supported encounters seem to be shorter. 


\begin{tabular}{|l|c|c|c|c|c|c|}
\hline & Work & Reside & Family & Leisure & Finance & Assistance \\
\hline Adivsor01 & $1 . \mathrm{N}$ & $2 . \mathrm{N}$ & $3 . \mathrm{D}$ & $4 . \mathrm{N}$ & $5 . \mathrm{N}$ & $6 . \mathrm{N}$ \\
\hline Advisor02 & $1 . \mathrm{N}$ & $2 . \mathrm{N}$ & $3 . \mathrm{D}$ & $4 . \mathrm{N}$ & $5 . \mathrm{N}$ & $6 . \mathrm{D}$ \\
\hline Advisor03 & $4 . \mathrm{N}$ & $1 . \mathrm{N}$ & $2 . \mathrm{A}$ & $3 . \mathrm{N}$ & $5 . \mathrm{N}$ & - \\
\hline Advisor04 & $3 . \mathrm{N}$ & $4 . \mathrm{N}$ & $5 . \mathrm{N}$ & $2 . \mathrm{N}$ & $1 . \mathrm{N}$ & - \\
\hline Advisor05 & $2 . \mathrm{N}$ & $3 . \mathrm{N}$ & $4 . \mathrm{N}$ & $5 . \mathrm{N}$ & $1 . \mathrm{N}$ & $6 . \mathrm{N}$ \\
\hline Advisor06 & $2 . \mathrm{N}$ & $1 . \mathrm{N}$ & $3 . \mathrm{N}$ & $4 . \mathrm{D}$ & $5 . \mathrm{N}$ & $6 . \mathrm{N}$ \\
\hline Advisor07 & $1 . \mathrm{N}$ & $2 . \mathrm{N}$ & $3 . \mathrm{N}$ & $4 . \mathrm{N}$ & $5 . \mathrm{N}$ & $6 . \mathrm{N}$ \\
\hline Advisor08 & $2 . \mathrm{N}$ & $3 . \mathrm{N}$ & - & $4 . \mathrm{N}$ & $1 . \mathrm{N}$ & $5 . \mathrm{N}$ \\
\hline Advisor09 & $3 . \mathrm{D}$ & $2 . \mathrm{D}$ & - & $4 . \mathrm{A}$ & $1 . \mathrm{N}$ & $5 . \mathrm{N}$ \\
\hline Advisor10 & $1 . \mathrm{N}$ & $2 . \mathrm{N}$ & $3 . \mathrm{D}$ & $4 . \mathrm{N}$ & $5 . \mathrm{N}$ & $6 . \mathrm{N}$ \\
\hline Advisor11 & $1 . \mathrm{N}$ & $2 . \mathrm{N}$ & $3 . \mathrm{D}$ & $4 . \mathrm{A}$ & $5 . \mathrm{N}$ & $6 . \mathrm{D}$ \\
\hline Advisor12 & $1 . \mathrm{N}$ & $2 . \mathrm{N}$ & $3 . \mathrm{A}$ & $4 . \mathrm{N}$ & $5 . \mathrm{N}$ & - \\
\hline Advisor13 & $4 . \mathrm{N}$ & $1 . \mathrm{N}$ & $2 . \mathrm{N}$ & $3 . \mathrm{N}$ & $5 . \mathrm{N}$ & $6 . \mathrm{N}$ \\
\hline Advisor14 & $1 . \mathrm{N}$ & $2 . \mathrm{N}$ & $3 . \mathrm{N}$ & $4 . \mathrm{N}$ & $5 . \mathrm{N}$ & - \\
\hline Advisor15 & $3 . \mathrm{N}$ & $2 . \mathrm{N}$ & $6 . \mathrm{D}$ & $1 . \mathrm{N}$ & $4 . \mathrm{N}$ & $5 . \mathrm{N}$ \\
\hline Advisor16 & $2 . \mathrm{N}$ & $3 . \mathrm{N}$ & $4 . \mathrm{N}$ & $1 . \mathrm{N}$ & $5 . \mathrm{N}$ & $6 . \mathrm{N}$ \\
\hline
\end{tabular}

Table 1: Summary of the topic order discussed in the last IT-session of each advisor. $\mathrm{N}$ : discussed and noted information in the mind-map, D: discussed information but not noted in the mind-map, A: asked about, but no information provided, - : not discussed at all. The numbers represent the sequential order of occurrence in the conversation.

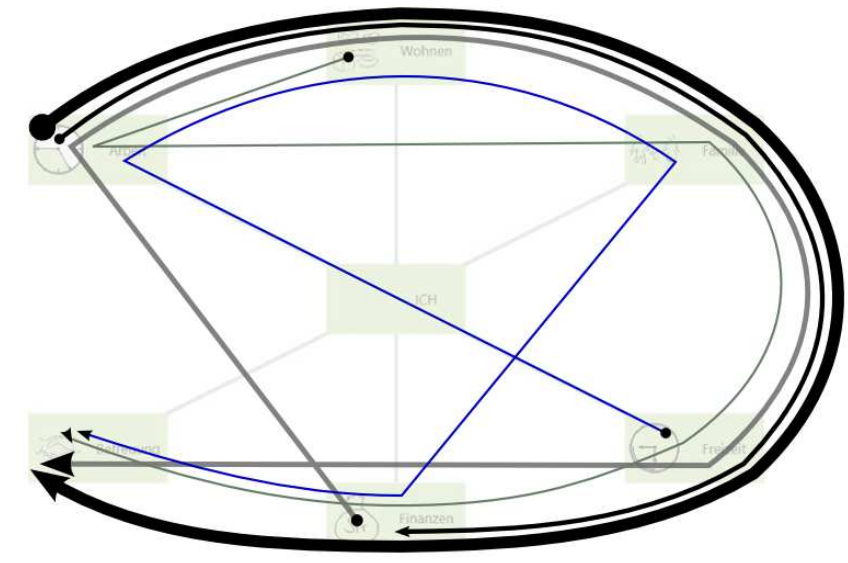

Figure 5: Visualized path of 11 clockwise conversation patterns. Thick lines visualize several occurrences of the same path. Patterns from the other 5 advisors were omitted.

The length of the sequences is determined by the number of continuous turn-takings while relating to the previous given answers. A sequence ends when the advisor switches to another topic without relating it to the previous content. An example could be an ongoing discussion about the employment situation terminated by the advisor by asking the client to provide details on his leisure time. Figure 7 shows that in IT-supported encounters more than half of the sequences are only of length one or two. This means that those sequences consist of a single question-answer pair with or without a following single turn-taking of asking and answering details.

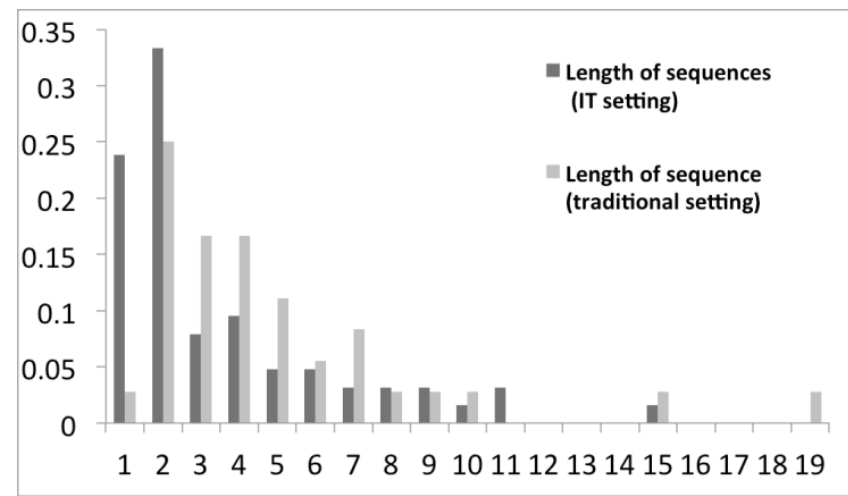

Figure 6: Relative distribution of length of conversation sequences (histogram) for traditional and IT-supported service encounter

In traditional encounters, however, the sequences tend to be longer. It has to be noted that one advisor had a completely different conversation style than the other 7 advisors that we analyzed. This particular advisor used pen and paper together with the IT-system. When discussing a topic, he made short notes on paper, and after a sequence was finished, he entered the data into the IT-system. This resulted in a conversation comparable to a traditional one with only 5 sequences of which two of them were exceptionally long, containing 10 and 15 turns. Removing this case from the sample, a Related Sample Wilcoxon Signed Rank Test supports the impression of the samples being longer within traditional encounter settings $(\mathrm{p}<=0.05)$ in pairwise comparison.

Regarding the discussion strategy within the IT setting, two groups of advisors are identifiable. The main difference 
between these groups is the appropriation of the mind-map to guide the conversation and the usage of the wording from the mind-map. Many conversation sequences begin with an explication of an inferred process in the IT setting. Typical statements at the beginning are "Then, we go to the next topic which is family" or "Next to residence". Analyzing the last sample, more than $39 \%$ of all sequences were motivated like that. Of those sequences, more than $77 \%$ had only one or two adjacent pairs (question-answer pairs) (cf. Figure 7) - a style we barely observed in traditional settings.

The other sequences resemble discussions with the client about his situation without any observable influence originating from the mind-map's structure. Parallel to the conversation, they fill out the provided information in the mind-map. This group asks more open questions like "Where do you live?" instead of "Let's go to the topic of residence", or "Have you already had experience with investments?" instead of "The last topic is assistance".

In some sessions, even clients expressed an adaption of a process structure. An exemplary statement is "Should I begin with work?" while pointing onto the touchscreen. Another participant asked, "Should I follow the pattern?" (while gesturing a path around the map). In some cases the clients pointed out that they, for example, have not yet talked about the family situation. When recognizing other information items relevant in their situation (like part time job, travel, or marriage), some of the clients mention them without being asked, such as having a plan to marry.

\section{Manifestation of coercing into completeness in interviews}

We have transcribed the audio-recorded interviews and analyzed them to find statements from advisors and clients regarding the phenomenon of coercing into completeness. Almost every advisor (13 of 16) reports on a strict process or a perceived obligation to fill out the mind-map completely or at least to talk about every topic. One advisor says, "For most young advisors it could be a benefit having to talk about all topics that would otherwise not be addressed". Another advisor declared, "For me it is too rigid; everything is predetermined". A third advisor talks about a "given schema" which guides the conversation. Yet another advisor compares the mind-map with a checklist: "With a checklist you ask the client how much he earns, you fill it out, and it is done. The mind-map has the same principle. You go through every branch, starting with one than the other. You are filling out each of them". One more statement supports this felt obligation: "You know exactly that you have to go through family and everything". One advisor also had the perception that he can follow the given process without having to think about it: "You do not have to think; everything is given". These statements show a strong perceived obligation to talk about every provided branch and the cognition of the mind-map as a checklist.

Besides some advisors, a substantial number of clients (15 of 48) also report in the interviews to have negative opinions concerning the mind-map design and stated that they would still prefer a traditional setting. Some statements from the clients are "The traditional advisory was more personal, maybe because the process was not so obvious", and "You go structurally through everything". Thus, some clients have the feeling of only filling out something without understanding why this should be necessary: "You only have to fill out something in a tool", "it was just a matter of filling out numbers and list the expenses", and "With the IT tool, some information was gathered that was not necessary. Not all of those questions were necessary to get to know each other". One client expresses that he has the feeling of being restricted while acting with the mindmap and that "one is restricted to the topics on the mindmap".

\section{Reasons for coercing into completeness in interviews}

In our interviews, we have identified statements from advisors which partly explain the phenomenon of coercing into completeness.

First, advisors do not want to forget to ask something important. Some advisors say that with the tool they ask for information that they otherwise would forget to ask. For example: "There are certainly three or four things I usually do not think about. I have been reminded". Another advisor reports that he is filling out everything because it reduces the risks of forgetting something: "You can fill out everything. What is in it is there. Then you cannot forget it". Interestingly, in the traditional advisory sessions the advisors do not act in the same manner. In the conventional, pen and paper-based session, it seems to be acceptable for the advisor not to ask for information, but in the ITsupported session they do not want to forget something, and therefore fill out the mind-map in a perfect manner.

Secondly, advisors report that it is much easier to retrieve information from the client. They report from reduced obstacles in the IT-supported setting: "The IT-tool is helpful to talk about certain topics and to analyze the situation without hesitation", and, "One dares to ask more directly to get an answer. In the traditional setting you are quicker satisfied if someone is shirking away. With IT I have to fill it out". Another advisor points out that the clients are willing to tell more in the IT-supported sessions: "The client is talking quicker about his family and leisure activities. I think he is more open because he sees: 'I also have to complete this field"'. One more statement regarding this aspect was mentioned: "I consider that one is asking the client with the IT-solution more precisely; you are expecting much more detailed answers".

The third reason, which we identified, is that many advisors have the perception that the client is expecting the advisor to talk about the topics: "It is not acceptable that I do not talk about some topics. I think this would be strange for the client". Other advisors identify the visual aspect of the mind-map as a reason for the perceived client expectation: "The client is seeing all topics of the mind-map and 
comments them on its own", and, "Because the field is represented there. The client said on its own that we still have to talk about the topic of family". Another statement, which stresses this perception, is the following: "If family is shown there, the client is asking himself: why does he not talk about this?" Moreover, the statement "The client can estimate what is expected of him" also hints into this direction for interpretation.

Fourth, one advisor has the perception of being monitored by the bank: "My supervisor would ask, 'Why have you not talked about his topic?' So it is possible to monitor me and see the missing topics".

\section{DISCUSSION}

Based on the rich data we gathered from the video analysis, interview statements, and observations presented in the results section, we make conjectures on the mechanisms that lead to the "coercing into completeness" phenomenon. By discussing the relevant findings and relating them to the existing literature, we aim to answer our two research questions: (1.) how the service encounter was affected through the phenomenon and (2.) why the phenomenon could still occur although the problem of rigid process visualization and enforcement is known in literature and was deliberately avoided in artifact construction. Finding explanations for this phenomenon is important, because ITsupported service encounters as such can bring great benefits to all stakeholders but must not interfere with the social setting at the same time, thereby deteriorating the otherwise successful collaboration. Financial advisory services need to be flexible to the clients' situation and their desires and goals.

According to our data, advisors liked our artifact and most of them appreciated the guidance from the system. However, a substantial amount of our clients still preferred the traditional setting and were concerned about the way their information was collected. Many of them stated that they perceived several discussed information items as unnecessary for the ongoing service. In general, we could not demonstrate in our data that the information provided by the client was any different between those settings. However, the way that information was retrieved turned out to be substantially different: While in the traditional settings we generally see a small number of long conversation sequences (where any further question to the advisor is highly related to the previous discussion within those sequences), in the IT-supported counterpart the conversation is much more fragmented. This style of conversation is characterized by a large number of very short question-answer pairs. As those sequences are not well related to each other, this style of conversation resembles the discourse structure based upon a structured questionnaire. As the artifact does not enforce (or even visualize) any representation of a process but the ITsupported conversation is heavily related to the content presented within the tool, our main conjecture is that those content structures are the cause of the observed phenomenon.

\section{Content structures coerce for completeness.}

Traditional service encounters are typically executed in an isolated environment. Only the client and the advisor are present. The information and topics that were discussed stay private, except for a written documentation of the advisory encounter prepared by the advisor afterwards, which is filed in the bank's CRM system. Therefore, the quality of the service encounter itself can only be directly controlled through the participants. However, we generally assume that the client only has a vague and limited idea of what a good advisory service should consist of. Thus, the appraisal of the service quality strongly relies on the role of the advisor and his skills.

When technology is introduced in such service encounters, different mechanisms may emerge. With our IT-artifact of an advisory support system we did not only support the activities of clients and advisors but also injected a content structure into the setting. Initially, we intended this structure to serve as a help to organize the objectified topics of a discussion. But actually, we thereby unintentionally fostered a coercing into completeness as expressed by the interview statements from the participants: Both clients and advisors inferred a notion of completeness from that given structure and even more worrying a notion of service quality. Some clients and advisors seemed to agree that a good service needs to cover all items from the given structure. We attribute this to the perception that the advisory service is no longer delivered in a private dyadic setting but is rather directly connected with the institutional quality standards through the IT-artifact. And since the design of the artifact is also influenced by the institution, its norms and values ("spirit" of the design) are embedded within the artifact itself. Hence, we can understand the perception that any given element within a structure is included for a reason and - being visible to the client and advisor simultaneously — might be perceived as equally stimulating and important. We found at least two driving forces within the interviews and observations that help to explain the phenomenon of coercing into completeness from this perspective, which we will present in the following sections.

First of all, in the IT-supported sessions, some advisors had the perception that it is easier for the bank to control if they are doing their jobs correctly. One advisor explicitly feared that her performance could be measured along the structure by their principals later on; she feared that she might need to explain why she omitted to discuss some items on the structure. From a client perspective it also seems unreasonable to omit items in a given structure. As we could observe during the evaluation, some clients explicitly asked the advisor why an object was omitted and demanded an explanation for what it was intended for. Thus, both participants seem to treat the given content structure as the 
gold-standard for quality. We call this the "invisible third participant", who influences the course of the advisory service through the spirit embedded in the artifact and provokes the phenomenon of coercing into completeness.

\section{Content structures promote a process to reach "completeness"}

In traditional financial service encounters, the order of the topics to be discussed is highly individual and dynamic. None of the participants can prepare a definitive script as the course of the discussion emerges on-the-go, driven by events (like one party mentioning an interesting aspect) that sparks the motivation to follow this topic in the succeeding discussion. It remains a challenge and is the responsibility of the advisor to keep the discussion coherent and logically structured.

Content structures that manifest through the artifact seem to be willingly adapted by the advisors to implicitly guide the whole process and help them to retain a common thread. In our experiments, there were statements from the advisors directed to the clients that clearly back up this claim. We observed that the majority of the advisors, guided by the mind-map, followed the given structure item-by-item, and they even verbally marked the switch from one item to another. Thus, the process is not event-driven anymore and does not adapt to verbal statements made by the client. Therefore the process is much more fixed. An unhindered flow with natural conversational sequences - where given answers spark new questions - is hardly noticeable. With the tool we see processes where advisors ask the clients to tell them all relevant issues to a specific topic before switching abruptly to the next one. This "game" ends when there are no more items that need to be covered. Again, we attribute this observation to the dyad's participant's striving for completeness, albeit they bear different motivations.

Even worse, the mind-map's default structure with the six branches could be interpreted as a progress indicator with six sub-tasks. Like other progress indicators, a minimum and maximum ("no topics discussed" and "all topics discussed") are visualized at any time during the interaction, and therefore implicitly provide a notion of completeness and progress although never intended as such. Filling out nothing and leaving the map empty explicates the minimum state. Discussing about one branch or filling it out brings the participants one step further to task completion. Just talking about the topic of a branch or even filling it out with at least one information-item contributes to the participant's perception that this sub-task has been finished. It has to be noted that the discussion is far richer than the information entered into the system. However, this might also be solely explainable by the effort of entering data into the system and potential usability problems. As discussed in the related work section, progress indicators can have a positive influence on the motivation to complete tasks in a single user context. But in dyadic settings, this effect can negatively influence the collaboration. As previous design activities [,18,19] have demonstrated, the negative effect of explicit process representation (visible) can be dampened by implicit representations (hidden). However, the given content structure in our design led our participants to develop an unintended perception of having a process indicator visualized. The appropriation of this content structure as a process indicator representation can be explained by the adaptive structuration theory [4]. This effect was certainly not intended during the artifact's construction. We call this driving force "parasitic process and progress visualization".

\section{Content structures fixate the level of details}

In traditional financial service encounters, the level of detail on which items are discussed and written down on paper is based on a subjective perception of their relevance. Topics that are perceived more relevant than others are covered in greater levels of detail. A notion of completion is either implied by the perceived level of saturation on a given topic or the discussion is deliberately aborted due to time constraints.

Given the driving forces of the "invisible third participant" and the "parasitic process and progress visualization", a pattern emerges which causes concerns: Instead of adapting the level of detail to the relevance of the topics, we observed a uniformly low level of detail for all topics discussed. Referring to the related work, the information items are considered "sticky" [28] and thus hard to express for the client. It was our intention to facilitate the process of their explication by providing graphical stimulating icons in order to unhide and identify this sticky information. This should have been also happening by refining the map's content incrementally. But instead, most advisors added to each category only one or two items without adding more levels of hierarchy to the map.

In the light of a realistic model of financial advice giving and taking [13], this practice can be judged twofold: (a) it could serve as a help for unskilled advisors reminding them to elicit and capture the most basic information items; (b) but it constitute at the same time a threat to the performance of skilled advisors because they might be able to capture more information items within a convenient conversation in the traditional pen and paper setting and subsequent manual written documentation.

Judging on the low levels of actual information content recorded within the mind-map, we also assume that the average advisor performance with respect to captured information quality might be lesser compared to the traditional encounters and their subsequent manual documentation. However, this is subject to further research, as we do not have sufficient data from this evaluation. We call this "dilution".

\section{CONCLUSION}

In this article, we report on the phenomenon of coercing into completeness. The phenomenon emerged in the context 
of IT-supported financial service encounters. A carefully designed IT-artifact could successfully support the first phase of financial service encounters (information collection phase) but negatively influenced the participant's collaboration as they tended to strive for reaching completeness. We identified content structure as the cause for the observed three effects. This conclusion is also based on the results of our evaluation and the literature. In collaborative situations, content structures can induce severe and unintended effects, such as (a) the identified invisible third participant, (b) the parasitic process and progress visualization, and (c) possibly lead to a decrease in information quality. Therefore, a central design implication for future systems is that any form of predefined structures has the potential to be interpreted as rigid process structures. Thus, care has to be taken when presenting predefined content structures within those artifacts. This finding extends the current research, as non-sequential process visualizations have been thought to be unproblematic within those settings in general. Nevertheless, we could demonstrate one case where this conjecture does not hold. Even worse, a hierarchical structure, which never was intended as a process representation has been perceived as such. Through this evaluation, we have also shown how difficult it can be to construct non-trivial artifacts while maintaining the quality of collaboration in socially sensitive settings.

We also respect the necessity to provide structures in some way within the artifact to enhance transparency and thus diminish information asymmetry and the principal-agent conflict [19]. We conclude that there will be a tradeoff in the design between the provision of structures for desired outcomes and the endangerment of social interactions. When predefined structures cannot be avoided, proper and special training of the advisors seems to be crucial for dealing with these problems on an organizational level. We assume this because we observed a few advisors neglecting the structure as guidance completely and using their usual discourse practices from traditional pen and paper encounters. They interpreted the spirit in another way and used the structure only to fill in the gathered information like using a notebook. Also, due to the fact that none of the advisors recognized this disruptive style of conversation by themselves, we do not assume that the problem vanishes by itself solely due to rising work experience with the artifact.

We assume our findings are generalizable to other advisory service encounters as well (like physicians, assurances, travel agencies, etc.) whenever technological artifacts are to be designed. With our contributions, we extend the current state of knowledge on how design aspects of such artifacts and how those artifacts can influence the behavior of the encounter's participants. More specifically, we shed light on the harmful role of content structuring in advisory encounters.

\section{LIMITATIONS}

The external validity of this research is limited by the fact that the evaluation was carried out in a laboratory setting. Apart from that, the evaluation was carried out realistically with real and experienced advisors and potential customers. Also, during the design of the artifact the management of the bank was involved. Statements from the advisors suggest that they behaved as if they were still in their organizational context. Although it was an experiment, the setting was close to reality. We are aware of the fact that the clients from this experimental evaluation were undergraduate students, and thus a relatively homogenous group compared to average bank clients. For example, in this group it is unlikely that clients have children, but the advisor still felt obligated to cover this topic. Due to the experimental environment one could argue that the advisors might have felt to be urged to use the artifact completely. However, this seems unlikely, as the advisors provided numerous reasons why they coerced for completeness but no single one attributed it to the experimental setting.

\section{REFERENCES}

1. Briggs, R.O., De Vreede, G.-J., and Nunamaker Jr, J. Collaboration engineering with ThinkLets to pursue sustained success with group support systems. J. of Management Information Systems 19, 4 (2003), 31-64.

2. Briggs, R. and Schwabe, G. On expanding the scope of design science in IS research. Service-Oriented Perspectives in Design Science Research, (2011), 92106.

3. Buisine, S., Besacier, G., Najm, M., Aoussat, A., and Vernier, F. Computer-supported creativity: Evaluation of a tabletop mind-map application. In Engineering Psychology and Cognitive Ergonomics. Springer Berlin Heidelberg, (2007), 22-31.

4. DeSanctis, G. and Poole, M.S. Capturing the complexity in advanced technology use: Adaptive structuration theory. Organization Science, 5.2 (1994), 121-147.

5. De Vreede, G. and Briggs, R.O. Collaboration engineering: Designing repeatable processes for highvalue collaborative tasks. System Sciences, 2005. HICSS'05. Proceedings of the 38th Annual Hawaii International Conference on, IEEE (2005), 17c-17c.

6. Eisenhardt, K.M. Agency theory: An assessment and review. Academy of Management Review, 14.1 (1989), $57-74$.

7. Ferster, C.B., Skinner, B.F., Harvard University, United States, and Office of Naval Research. Schedules of reinforcement, by C. B. Ferster and B. F. Skinner. Appleton-Century-Crofts, New York, (1957).

8. Gafni, A., Charles, C., and Whelan, T. The physicianpatient encounter: The physician as a perfect agent for 
the patient versus the informed treatment decisionmaking model. Social Science \& Medicine, (1998).

9. Giddens, A. The constitution of society: Outline of the theory of structuration. University of California Press, Berkeley, (1984).

10. Gregor, S. and Hevner, A. Positioning and presenting design science research for maximum impact. Management Information Systems Quarterly 37, 2 (2013), 337-355.

11. Heinrich, P., Kilic, M., Aschoff, F.-R., and Schwabe, G. Enabling relationship building in tabletop-supported advisory settings. Proceedings of the 17th ACM Conference on Computer Supported Cooperative Work \& Social Computing, ACM (2014), 171-183.

12. Hevner, A.R., March, S.T., Park, J., and Ram, S. Design science in information systems research. MIS Quarterly 28, 1 (2004), 75-105.

13. Jungermann, H. Advice giving and taking. Proceedings of the 32nd Annual Hawaii International Conference on System Sciences, 1999. HICSS-32, IEEE (1999).

14. Littler, C.R. Understanding Taylorism. The British Journal of Sociology 29, 2 (1978), 185.

15. Myers, B.A. The importance of percent-done progress indicators for computer-human interfaces. Proceedings of the SIGCHI Conference on Human Factors in Computing Systems, ACM (1985), 11-17.

16. Novak, J. Mine, yours... ours?: Designing for principalagent collaboration in interactive value creation. Wirtschaftsinformatik 2009, Vienna, Austria, 25 February 2009 - 27, (2009).

17. Nussbaumer, P. Essays on Transparent IT Support for Asymmetric Client-advisor Encounters: The Case of Swiss Investment Advisory Services. Doctoral dissertation, (2012).

18. Nussbaumer, P. and Matter, I.S. What you see is what you (can) get?: Designing for process transparency in financial advisory encounters. Interact 2011, (2011).

19. Nussbaumer, P., Matter, I., and Schwabe, G. "Enforced" vs."casual" transparency: Findings from IT-supported financial advisory encounters. ACM Transactions on Management Information Systems (TMIS) 3, 2 (2012), 11.

20. Oehler, A. and Kohlert, D. Financial advice giving and taking: Where are the market's self-healing powers and a functioning legal framework when we need them? Journal of Consumer Policy 32, 2 (2009), 91-116.

21. Peffers, K., Tuunanen, T., Gengler, C.E., et al. The design science research process: A model for producing and presenting information systems research. Proceedings of the First International Conference on Design Science Research in Information Systems and Technology (DESRIST 2006), (2006), 83-106.

22. Peffers, K., Tuunanen, T., Rothenberger, M.A., and Chatterjee, S. A design science research methodology for information systems research. Journal of Management Information Systems 24, 3 (2008), 45-77.

23. Prahalad, C.K. and Ramaswamy, V. Co-creation experiences: The next practice in value creation. Journal of Interactive Marketing 18, 3 (2004), 5-14.

24. Schmidt-Rauch, S. and Nussbaumer, P. Putting value co-creation into practice: A case for advisory support, ECIS 2011 Proceedings. Paper 138. (2011).

25. Skinner, C.H. An empirical analysis of interspersal research: Evidence, implications, and applications of the discrete task completion hypothesis. Journal of School Psychology 40, 4 (2002), 347-368.

26. Suchman, L. Do categories have politics? Computer Supported Cooperative Work (CSCW) 2, 3 (1993), 177190.

27. Tallon, P.P. A service science perspective on strategic choice, IT, and performance in U.S. banking. Journal of Management Information Systems 26, 4 (2010), 219252.

28. Von Hippel, E. "Sticky information" and the locus of problem solving: Implications for innovation. Management science, (1994), 429-439.

29. Weber, W.G. Organizational conditions fostering prosocial work orientations in teams. Innovative Theories, Tools, and Practices in Work and Organizational Psychology. Seattle, WA: Hogrefe and Huber, (2000), 75-96.

30. Winograd, T. Categories, disciplines, and social coordination. Computer Supported Cooperative Work (CSCW) 2, 3 (1993), 191-197.

31. WpHG. Wertpapierhandelsgesetz in der Fassung der Bekanntmachung vom 9. September 1998 (BGB1. I S. 2708), das zuletzt durch Artikel 2 Absatz 44 des Gesetzes vom 22. Dezember 2011 (BGB1. I S. 3044) geändert worden ist. 2011.

32. Zeigarnik, B. On finished and unfinished tasks. In $A$ Source Book of Gestalt Psychology, (1938) ed. WD Ellis, pp. 300-314. New York: Harcourt, Brace \& World (Reprinted and condensed from Psychol. Forsch. 9:1-85). 